\title{
Tenthredo (Linné, 1758) species from Chopta, India (Hymenoptera: Symphyta: Tenthredinidae)
}

\author{
Attila Haris ${ }^{1} \&$ Malkiat S. SAINI ${ }^{2}$ \\ ${ }^{1} \mathrm{H}-1076$ Budapest, Garay utca 19 2/20, Hungary \\ e-mail: attilaharis@yahoo.com \\ ${ }^{2}$ Department of Zoology, Punjabi University,147 002 Patiala, India \\ e-mail: saini20@hotmail.com
}

Haris, A. \& Malkait. S. S.: Tenthredo (Linné, 1758) species from Chopta, India (Hymenoptera: Symphyta: Tenthredinidae).

Abstract:Tenthredo triangulum spec. nov., Tenthredo nefrostigmata spec. nov., and Tenthredo alboaspida spec. nov. are described from Chopta, India and compared to Tenthredo victoriae Malaise, 1945, Tenthredo maw Vasu \& M. S. Saini, 1998, Tenthredo chloralancenia Wei, 1998, Tenthredo subflava ssp. victorialis Malaise, 1945, Tenthredo waltoni Malaise, 1945 and Tenthredo rubiobitava Wei, 2002. Tenthredo shensiensis Malaise, 1945 is new record for India.

Keywords: Hymenoptera, Symphyta, Tenthredinidae, Tenthredininae, Tenthredo, India, Chopta, new species.

\section{Introduction}

The material of the present paper is collected by Dr. Malkiat S. Saini in Chopta, Uttarkhand state of India. Chopta (Fig. 1) is a small village situated at an altitude of about $2680 \mathrm{~m}$ above MSL. This is beautiful lush green high altitude area of Kedarnath Wildlife Sanctuary falling in the District Rudraprayag of Uttarakhand. It is situated in the Garhwal Hills under the canopy of conifers, it is covered by snow usually from November to March. Low lying vegetation consisting of variety of herbs and broad leaved shrubs, is very thick and infested with leaches. The best season of sawfly collection is June \& July.

\section{Material and methods}

The material consists of 9 specimens of 8 species, all of them belong to genus Tenthredo Linné, 1758. After preselection and previous classifiction Dr. Saini sent to A. Haris the material for further analysis. As a result, 8 species were identified, one of them is new record for the fauna of India, four species has already known from India and three 
species proved to be new for science.

For identification, the comprehensive works of MALAISE (1945) and SAINI (2007) were consulted completed with high number of subrecently published papers mainly from Chinese authors (Wei \& Nie, 1998, Wei, Wen \& Deng 1999, Wei 2002a, b and many others, due to the extremely high number of papers, we could not list all of them, only the most relevants for our present study).

For the subgeneric calssification we applied the mostly accepted system of Zhelochovtsev (ZHELOCHOVTSEV 1988).

Holotypes, paratypes and voucher specimens are deposited at ZSI ( Zoological Survey of India) Solan (H.P).

Both authors are author of the new species: ie. Haris and Saini.

\section{Abbreviations:}

IATS: Inner apical tibial spur

ICD: Inter cenchri distance

IDMO: Interocular distance at level of median ocellus

ITD: Inter tegular distance

LID: Lower interocular distance

MB: Metabasitarsus (length)

OATS: Outer apical tibial spur (length)

OCL: Ocello occipital line

OOL: Oculoocellar line

POL:- Post ocellar line

\section{Description of the new species}

Tenthredo triangulum spec. nov.

(Figs. 2, 3 and 4)

Holotype: female, India, Chopta, 2680 m., 23. 06. 2015. Leg.: M. S. Saini.

Head pale straw colored (in life green). Head in dorsal view covered with large black spot covering vertex, temple, suprantennal tubercles and frontal area leaving narrow inner orbit. Mouthparts pale. Antenna entirely black. Thorax pale green. Black: longitudinal line on mesopleuron, dorsal line in middle of pronotum, triangular lateral spots on corners of pronotum, middle spot on tegula, anterior lobes of mesonotum except its V-shaped hind margin, lateral lobes of mesonotum, basal subtriangular spot on mesoscutellum, depressed part of mesonotum and metanotum. Legs straw colored, black: longitudinal line on all femora, longitudinal line on hind coxa. Abdomen straw colored with rusty red 4 apical segments, black: first segment (propodeum) except pale oval large central spot on hind margin, narrow anterior margins of segments 2-6 with triangular projections laterally (1-1) and centrally (1). Ovipositor rusty red. Wings hyaline, costa and stigma brownish yellow. Veins blackish brown. Head (frontal area, supraantennal tubercles, inner orbits, temples and vertex) with very dense, moderately deep punctures without shiny interspaces matt on black coloured area. The light area of head (supraclypeal area, face, genae) unpunctured, shiny. Head contracted behind eyes. Clypeus and labrum sparsely punctured with moderately large, shallow punctures, shiny. Supraantennal tubercles and frontal ridges confluent and elevated. Mesopleuron, pronotum, propleuron, mesosternum and metapleuron with minute, dense hardly visible shallow punctures, strongly shiny. Anterior and lateral lobes of mesonotum, mesoscutellum 


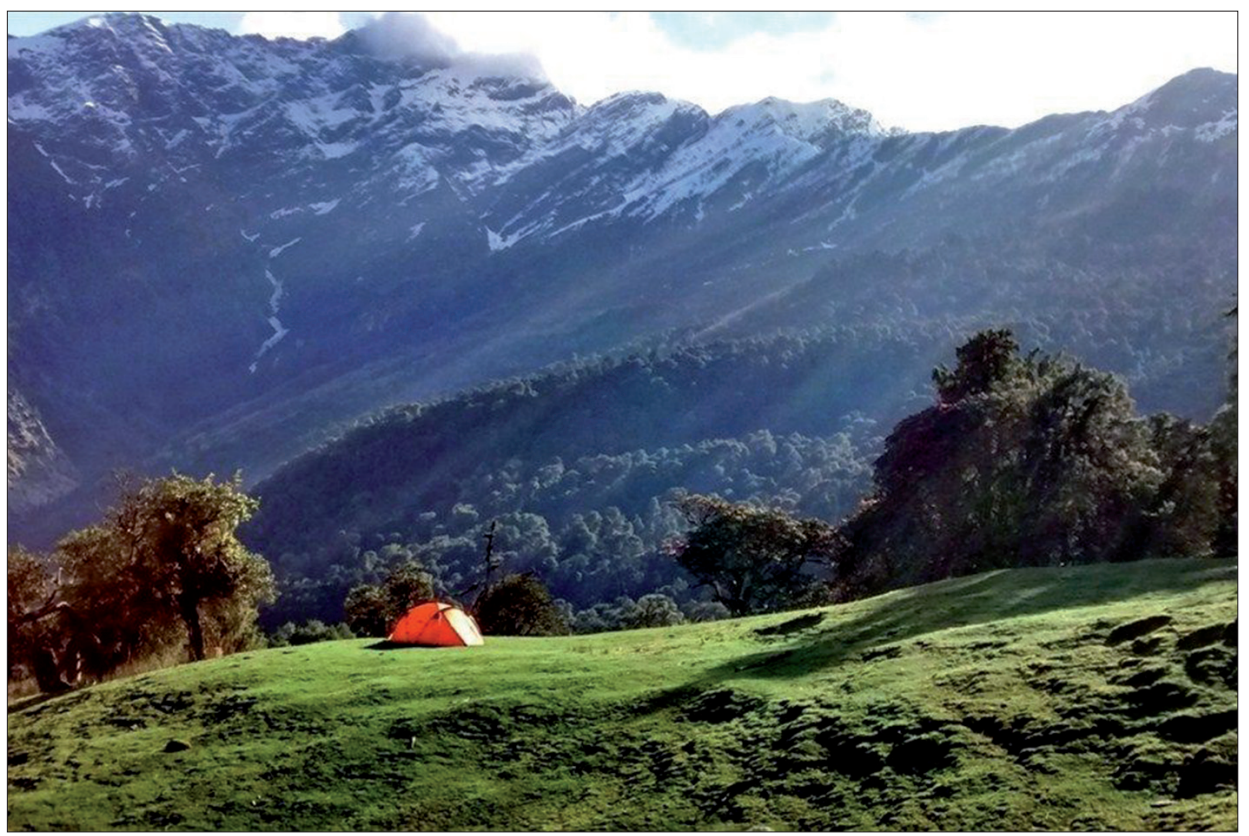

Fig. 1: Chopta: collecting site (photo: Saini)

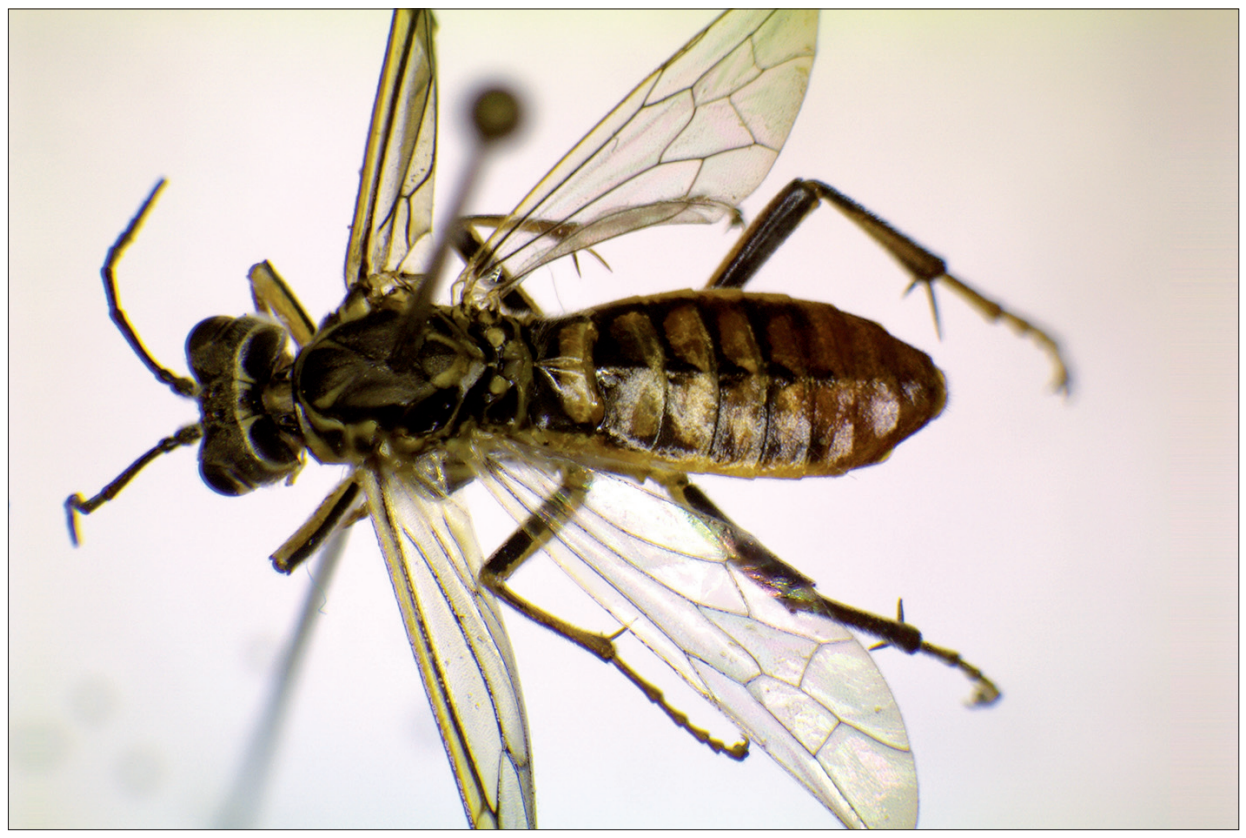

Fig. 2: Tenthredo triangulum spec. nov. holotype in dorsal view (photo: Haris) 


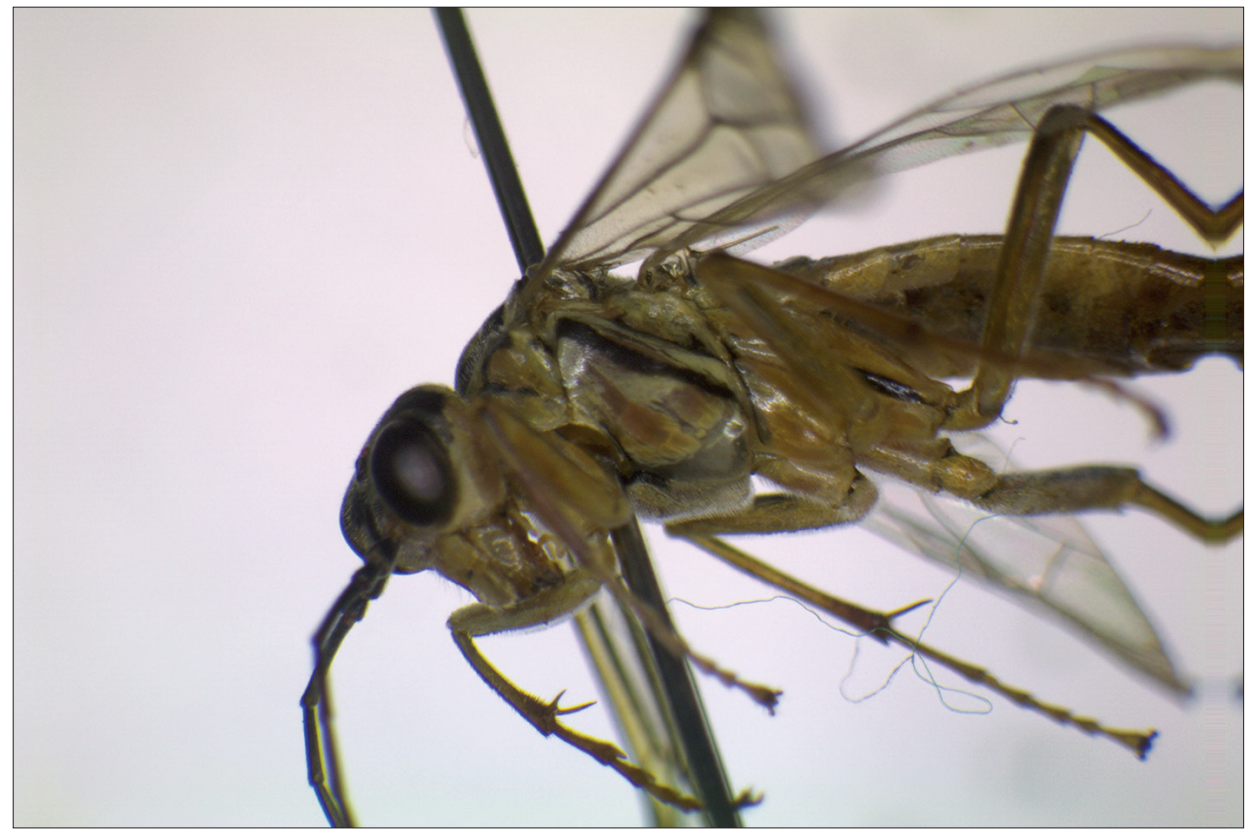

Fig. 3: Tenthredo triangulum spec. nov. holotype in lateral view (photo: Haris)

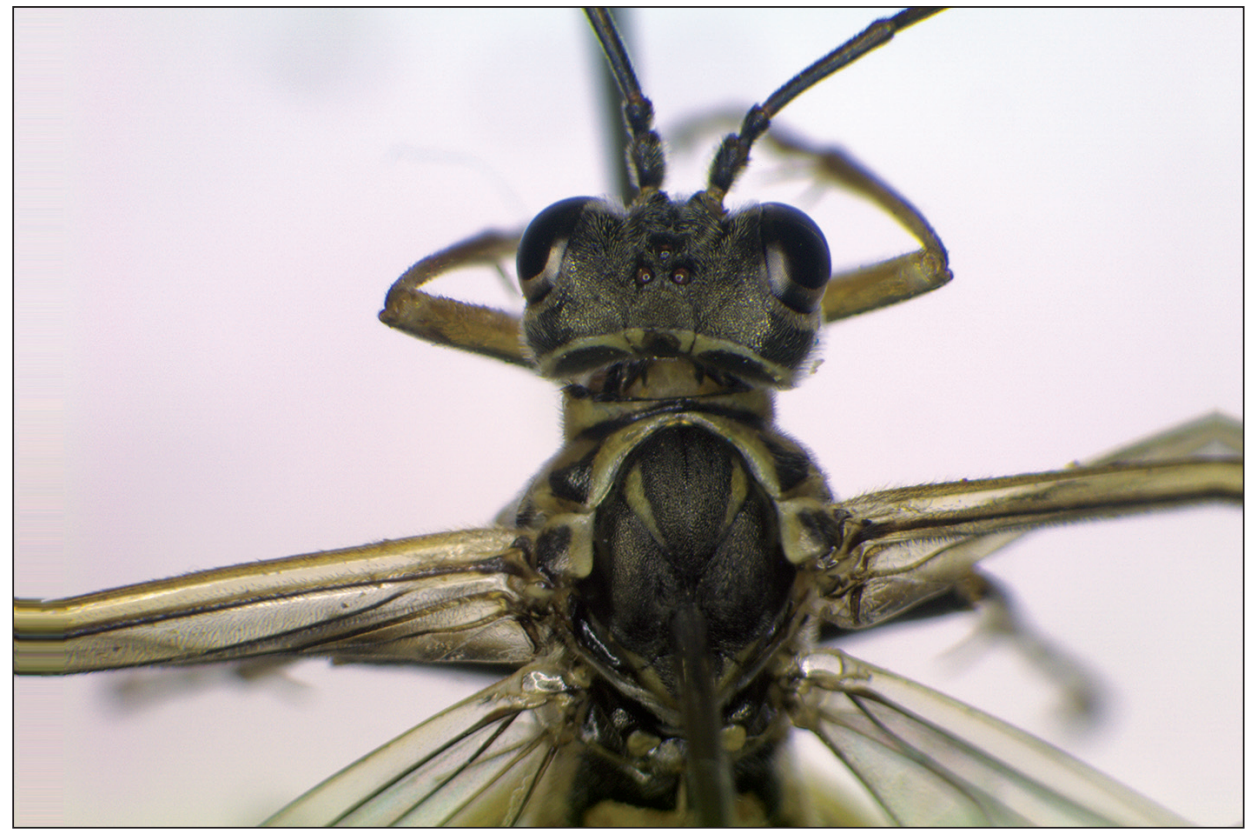

Fig. 4.: Head of Tenthredo triangulum spec. nov. (photo: Haris) 
densely granulated, matt. Mesoscutellar appendage transversaly wrinkled, shiny. Metanotum smooth and shiny. Metascutellum smooth and shiny with longitudinal carina, alongside this carina with minute dense punctures. Head and thorax covered with white short and sparse pubescence. Propodeum smooth and shiny. Other tergites with very fine, shallow and dense surface sculpture, shiny. Mesoscutellum pyramidally elevated with blunt apex and longitudinal carina. Mesopleuron strongly but bluntly elevated. Mesosternum without thorns. Postoccipital carina complete, on temples and vertex occipital carina expressed by white line. Ratios of antennal segments 1-9: $17: 10: 41: 30$ : $22: 19: 17: 17: 15$. OOL : POL : OCL: $9: 2: 6$. Width : length (longitudinal measure) of the postocellar area: $5: 3$. Longest diameter of eye : length of 3rd antennal segment: $42: 41$. Ratios of hind tarsal segments $1-5$ without claws: $60: 24: 20: 14:$ missing. Length of gena : diameter of anterior ocellus: $3: 5$. Depth of clypeal emargination : median length of clypeus: $12: 25$. Length of hind tibia : length of ovipositor: $70: 33$. LID :IDMO: EL: $37: 53: 42$. ICD : ITD = $14: 48$. IATS : MB : OATS: $31: 60: 25$. Antenna slender, about as long as than length of head, thorax and first 2 abdominal segments (propodeum and 1st segment) combined. Subapical tooth of claw wider and shorter than apical. Length: $11.6 \mathrm{~mm}$.

The new species belongs to subgenus Tenthredella Rohwer, 1910 (ZHELOCHOVTSEV 1988).

The specific name refers to the triangular pattern of abdomen.

In Malaise (1945), the new species runs to Tenthredo victoriae Malaise, 1945. In Tenthredo victoriae Malaise, 1945 abdominal segments with wide black anterior margin without triangular pattern and there is a very sharp carina between mesopleuron and mesosternum, temples and mesosternum are light, mesoscutellum is white finally supraantennal tubercles are pale. In the new species, abdominal segments 2-6 with median and lateral triangular pattern, there is no carina between mesopleuron and mesosternum, temples, mesosternum, mesoscutellum mostly and supraantennal tubercles are black (except apical margin).

In Saini (2007), the new species runs to Tenthredo maw Vasu \& M.S. Saini, 1998. However, T. maw has completely different pattern on head (compare Fig. 4 with Fig. 330 in Saini (2007)), its antenna is stout but long and slender in the new species; the pattern of abdomen is also completely different in these 2 species, the characteristic abdominal coloration and pattern is completely missing from $T$. maw. Clypeal emargination only $0.25 \mathrm{x}$ as deep as clypeal median length in T. maw but this proportion is $0.5 \mathrm{x}$ in the new species.

It also resembles to Tenthredo chloralancenia Wei, 1998 (WEI \& NIE 1998).

In Tenthredo chloralancenia Wei, 1998, tergites 1-8 with triangular spots in middle, tergites without anterior black margins, apical abdominal segments are greenish yellow, apex of femora and tibiae are with black line and mesopleuron is flat. In the new species triangular spots are on lateral and anterior-central sides of tergites 2-6 and tergites with anterior black margines, apical 4 abdominal segments are rusty red, tibiae without black line but femora have longitudinal black line in their total length and mesopleuron is strongly elevated.

Tenthredo nefrostigmata spec. nov.

(Figs. 5, 6 and 7)

Holotype: female, India, Chopta, 2680 m. 23. 06. 2015. leg. M. S. Saini

Head straw colored (in life green) with characteristic two-lobes black pattern covering vertex, interocellar area, area between supraantennal tubercles and with 2 semicircular lobes not reaching eyes. Antenna black, only scape straw colored. Mouthparts straw colored. Thorax straw colored (green), black: middle horizontal line on pronotum and 


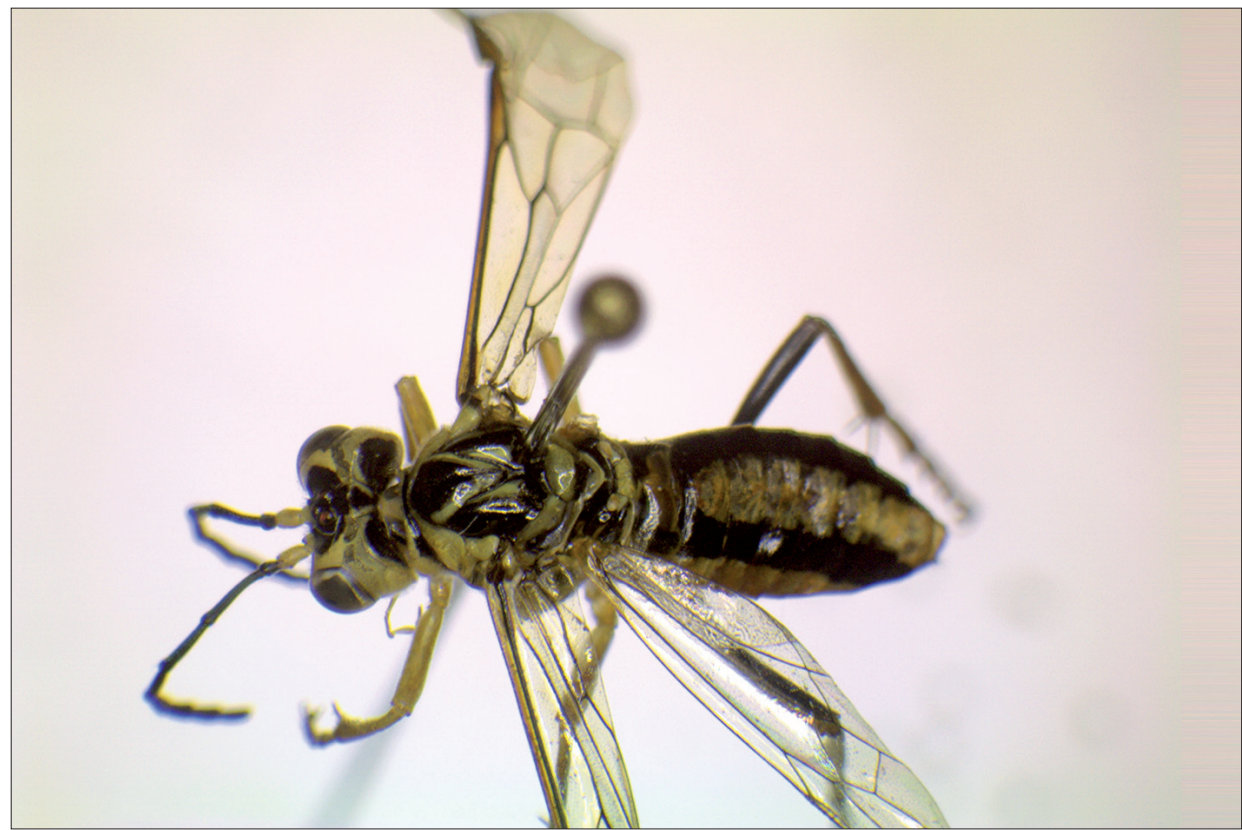

Fig. 5: Tenthredo nefrostigmata spec. nov. holotype in dorsal view (photo: Haris)

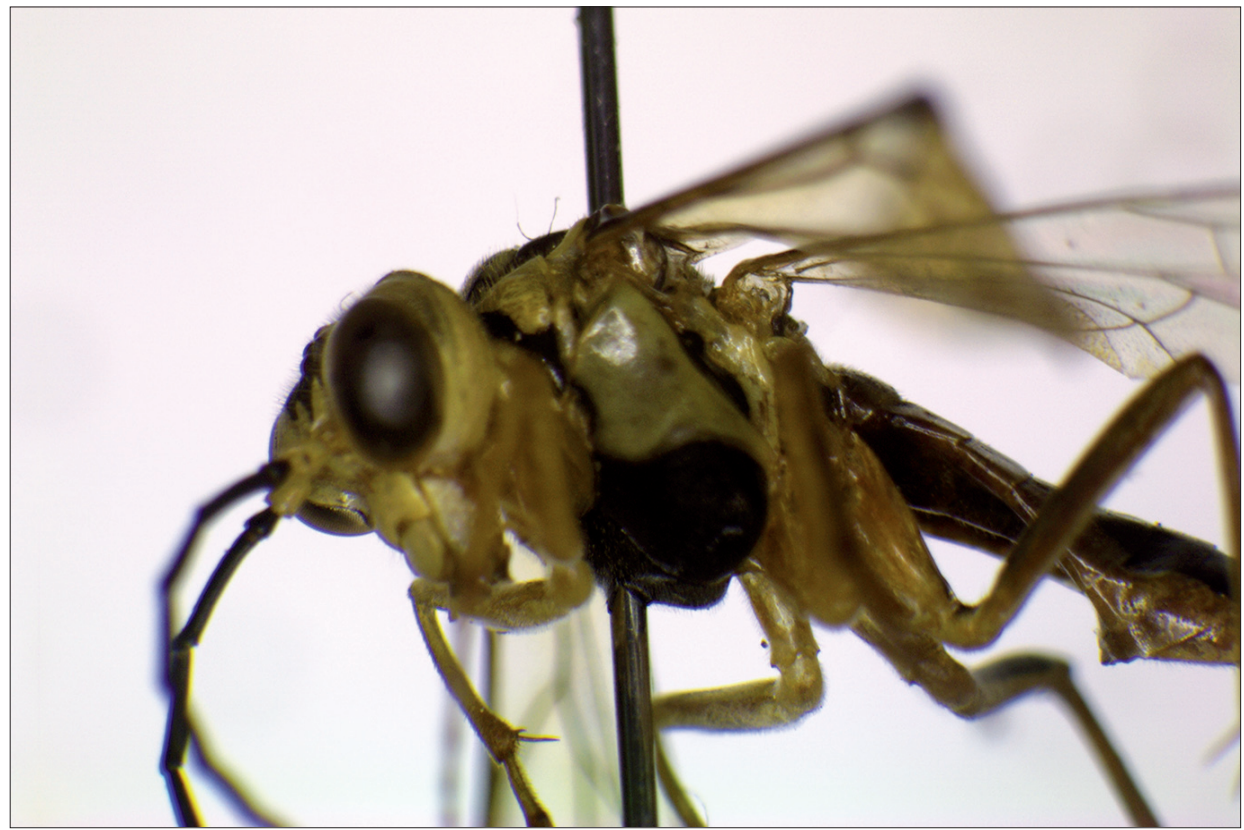

Fig. 6: Tenthredo nefrostigmata spec. nov. holotype in lateral view (photo: Haris) 


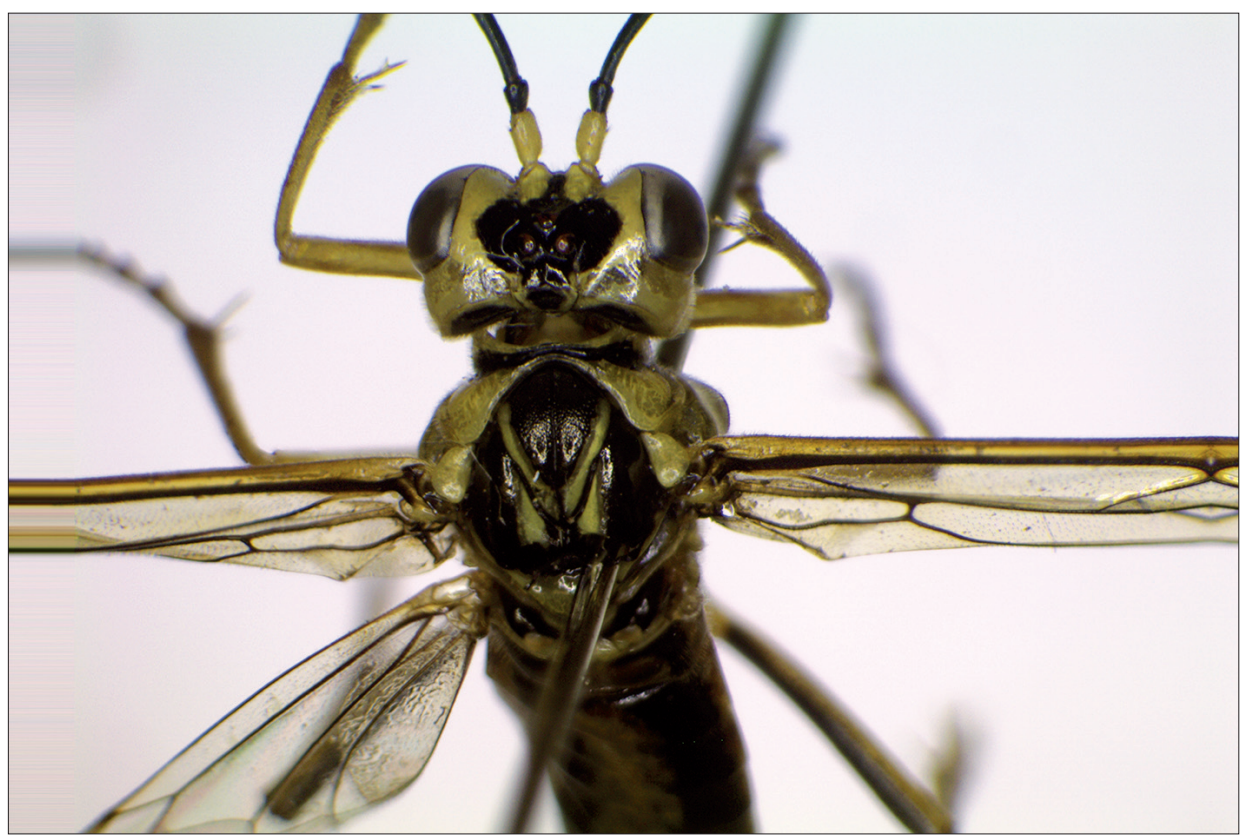

Fig. 7: Head of Tenthredo nefrostigmata spec. nov. (photo: Haris)

propleuron, anterior mesonotal lobes (except V-shaped hind margin), lateral mesonotal lobes (except triangular spots on inner corners), basal and apical transversal bands of mesoscutellum, basal band of mesoscutellar appendage, posterior part of depressed hind sides of mesonotum, metanotum (except triangular spots behind cenchri), apical third of metascutellum, mesosternum and katepimeron. Legs pale straw colored only hind femur with complete longitudinal black line and 1-1- small black spot on hind trochanter and hind coxa. Wings hyaline, costa and stigma semitransparent light brown, venation brownish black. Abdomen straw colored with 2 longitudinal black wide paralell band on lateral sides of all tergites (except last tergite), second tergite with an additional narrow black anterior margin. Wings hyaline, stigma and costa transparent light brown, veins brownish black. Head and thorax covered with sparse white pubescence approximtely $2 / 3 \mathrm{x}$ as long as diameter of anterior ocellus. All parts of head, including mouthparts, strongly shiny with moderately sparse minute shallow punctures. Punctures placed unevenly, distance between punctures 2-6x larger than diameter of a puncture. Pronotum and propleuron shiny unpunctured with shallow wrinkles. Anterior lobes of mesonotum shiny with minute, moderately dense shallow punctures, distance between puncture $1-2 x$ as large as diameter of a puncture. Lateral lobes of mesonotum, mesoscutellum, mesoscutellar appendage, metascutellum, metanotum, katepimeron and metapleuron smooth and shiny. Apical half of mesoscutellum with shallow wrinkles. Mesopleuron and mesosternum densely, very finely and shallowly punctured, shiny. Abdominal tergites (including propodeum) with very fine and shallow surface sculpture, shiny. Postoccipital carina complete, head contracted behind eyes. Supraantennal tubercles and frontal ridges confluent and elevated. Mesoscutellum pyramidally elevated with blunt apex. Mesopleuron strongly elevated with blunt apex. Mesosternal thorns missing. Mesoscutellum with horisontal carina. Ratios of antennal segments 1-9: $15: 7: 38: 34$ 
: $32: 26: 21: 20: 19$. OOL : POL : OCL: $9: 2: 5$. Width : length of postocellar area: $1: 2$. Ratios of hind tarsal segments (without claw): $33: 20: 15: 10: 18$. Length of ovipositor : length of hind tibia: $38: 55$. Depth of clypeal emargination : median length of clypeus: $3: 10$. Length of third antennal segment: maximal diameter of eye: $38: 50$. Gena linear, diameter of anterior ocellus : length of gena: $5: 1.5$. LID :IDMO: EL: 24 : $56: 50$. ICD : ITD $=17: 48$. IATS : MB : OATS: $18: 33: 16$. Subapical tooth of claws little but significantly shorter than apical. Length: $10.1 \mathrm{~mm}$.

The new species belongs to subgenus Eurogaster Zirngiebl, 1953.

The specific name refers to the kidney-shaped black pattern on head.

In Malise (1945), the new species runs to Tenthredo subflava ssp. victorialis Malaise, 1945. In opposite to Tenthredo subflava ssp. victorialis, the new species has no H-like spot on head (but kidney-like spots), apex of mesopleuron is not thorn-like (but blunt) and abdominal pattern is completely different: abdominal tergites without broad basal margins, but with 2 longitudinal band through all abdominal segments.

In Saini (2007), the new species runs to Tenthredo maw Vasu \& M.S. Saini, 1998, couplet 112, like the previous species. However, the differences of the 2 species are significant. In Tenthredo maw, frontal ridges low or missing; head subrugose and opaque; black are: antenna, except underside of segments 4-9. In the new species, antenna, except scape, black, head strongly shiny and frontal ridges are clearly marked. Frontal spot of Tenthredo maw is in Fig. 330 (SAINI 2007) compare with Fig. 7. In Tenthredo maw, abdomen green, black are anteromedial triangular spot on propodeum, narrow anterior margin of tergite 2 in middle and anterodorsal subrectangular spot on tergites 8 . In the new species, abdomen straw coloured with 2 longitudinal black wide parallel band on lateral sides of all tergites (except last tergite).

Tenthredo alboaspida spec. nov.

(Figs. 8, 9 and 10)

Holotype: female, India, Chopta, 2680 m. 01. 05. 2009. leg. M. S. Saini

Head ferruginous with 1-1 obscure blackish brown spot next to hind ocelli and between ocelli also with small black spot between antennae little above antennal level. Mouthparts ferruginous except white outer side of mandible. First 3 and base of 4th antennal segment black, other apical segments dirty yellowish white. Thorax ferruginous, black: metanotum, anterior half of propleuron; brown: anterior mesonotal lobe except ferruginous hind margin, lateral mesonotal lobes except ferruginous inner triangular spots; sunken part of mesonotum; white: mesoscutellum, mesoscutellar appendage, metascutellum, hind margin of pronotum. Legs ferruginous, black: longitudinal line on all femora (on hind femur wider) and on middle and hind coxe. Abdomen ferruginous, tergites 1-5 dominantly black (hind margin and few diffuse spots ferruginous), tergite 6 with central large black spot on anterior margin. Wings yellowish hyaline. Costa and stigma yellow, veins brown. Ovipositor ferruginous. Head above antenna very densely, moderately roughly, moderately deeply punctured, slightly shiny. Pronotum and propleuron moderately densely punctured with small and moderately deep punctures, shiny. Mesonotal lobes minutely granulated, matt. Mesoscutellum transversally wrinkled, matt. Mesoscutellar appendage with moderately sparse, deep and moderately large punctures, moderately shiny. Depressed part of mesonotum, metanotum and metascutellum smooth and shiny. Mesopleuron shiny, transversally wrinkled with few large and deep punctures. Mesosternum densely punctured with minute, moderately deep punctures, shiny. Abdominal tergites shiny, with fine transverse sculpture missing from propodeum. Propodeum shiny, with sparse oblique wrinkles. Head gently dilated than 


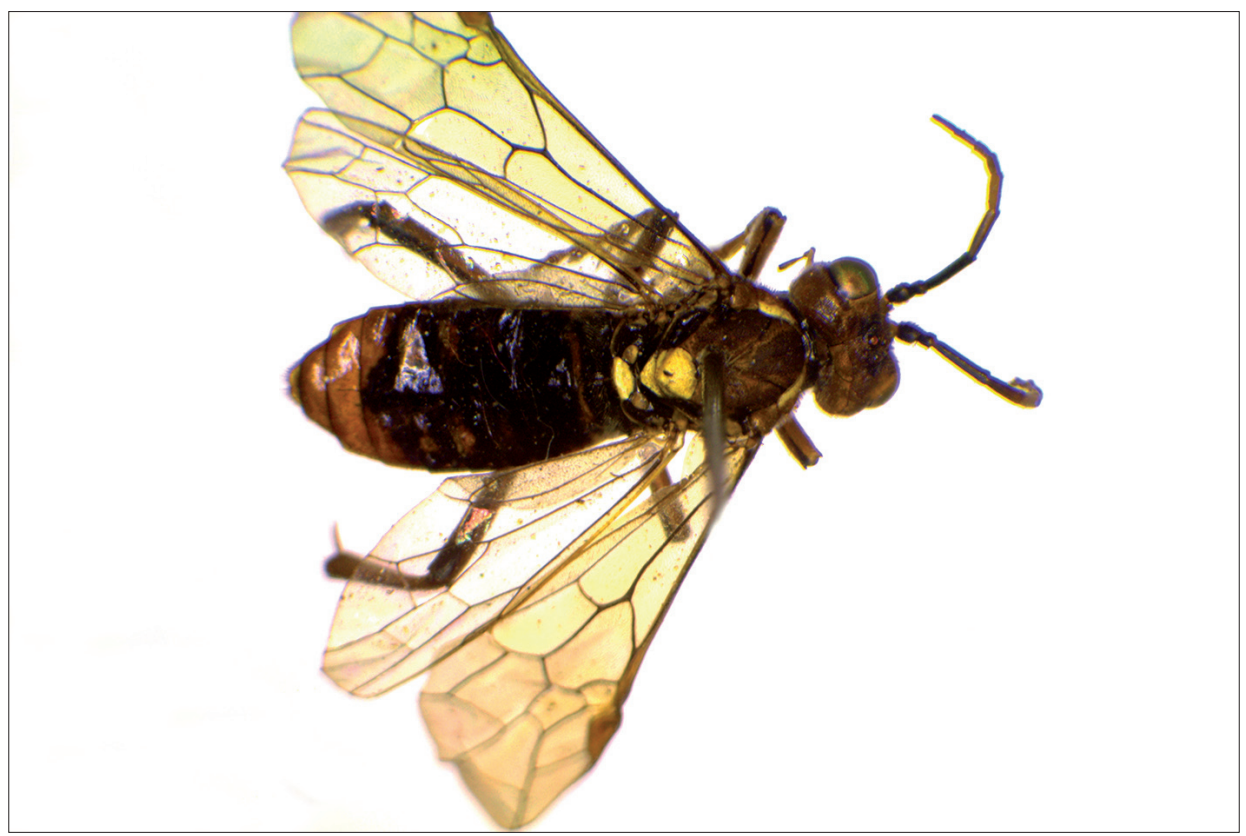

Fig. 8: Tenthredo alboaspida spec. nov. holotype in dorsal view (photo: Haris)

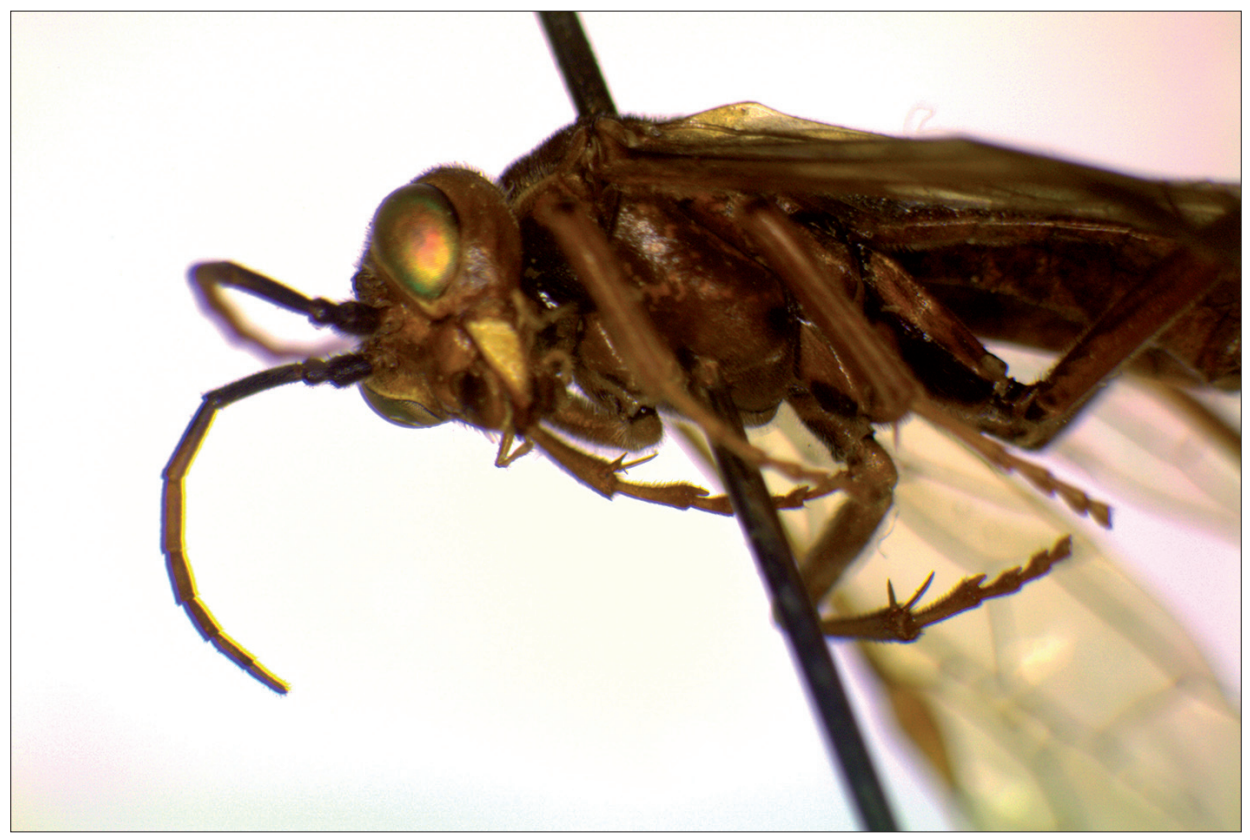

Fig. 9: Tenthredo alboaspida spec. nov. holotype in lateral view (photo: Haris) 


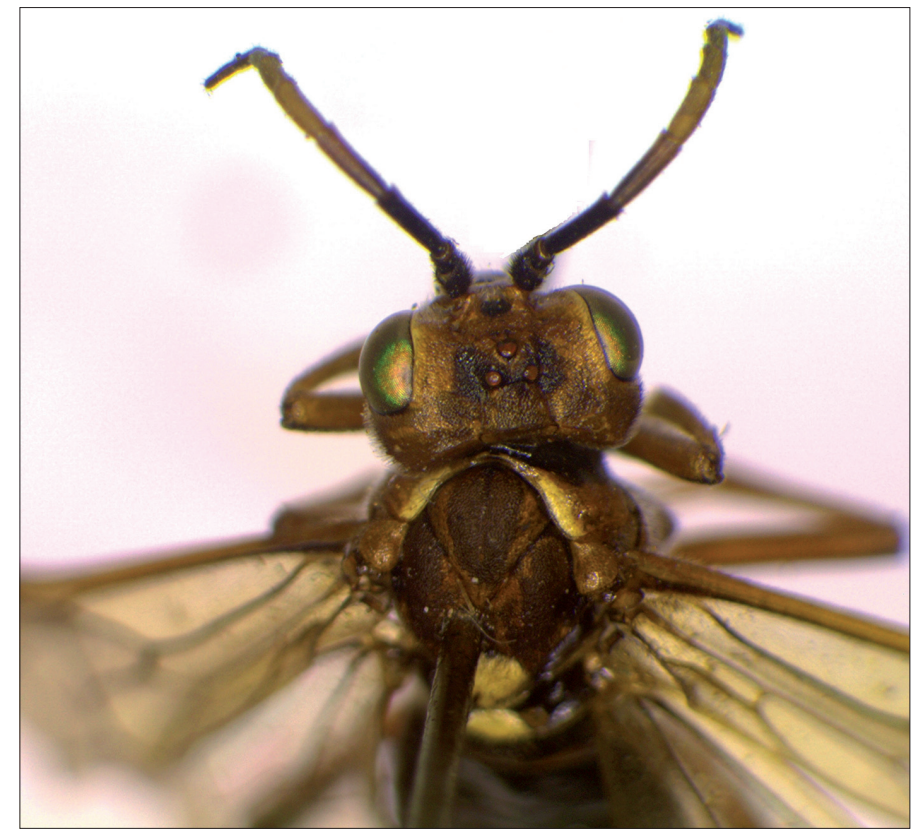

Fig. 10: Head of Tenthredo alboaspida spec. nov. (photo: Haris)

contracted behind eyes. Occipital carina complete. Ratios of antennal segments 1-9: 11 $: 6: 32: 25: 20: 15: 13: 13: 12$. Antenna about as long as head and thorax combined. OOL : POL : OCL: $16: 5: 11$. Length : width of postocellar area: $11: 17$. Length of $3 \mathrm{rd}$ antennal segment : longest diameter of eye: $32: 37$. Depth of clypeal emargination : median length of clypeus: $3: 10$. Clypeus roundly emarginated. Width of gena : diameter of anterior ocellus: $1: 1$. Head and thorax moderately densely covered with short, white pubescence. Mesoscutellum and mesopleuron bluntly elevated. Mesosternum without thorns. Length of hind tibia : length of ovipositor: 51 : 33. LID :IDMO: EL: 36 $: 49: 37$. ICD : ITD $=13: 42$. IATS : OATS: $29: 22$. Apical tooth of claw longer than subapical. Length: $9.4 \mathrm{~mm}$.

The new species belongs to subgenus Tenthredella Rohwer, 1910 (ZHELOCHOVTSEV 1988).

The specific name albospida means: white scutellum.

In Malaise (1945) and Saini (2007), the new species runs to Tenthredo waltoni Malaise, 1945 (couplets 79 and 51). In T. waltoni, the color is significantly different, for instance: mesoscutellum with anterior

$2 / 3$ pale and posterior $1 / 3$ black, base color of head is pale yellow, abdomen is ferruginous except blackish anterior $2 / 3$ of propodeum and medial spot on tergite 2 . In the new species, the mesoscutellum is entirely white, base color of head is ferruginous, first 5 tergites are nearly entirely black. In $T$. waltoni the clypeus is triangularly excised, in the new species the clypeal emargination is rounded.

The new species is related to Tenthredo rubiobitava Wei, 2002 either. The differences: T. rubiobitava has mesoscutellum, mesocutellar appendage and metascutellum black, not white as in the new species. Also the antenna in the new species is more extensively light colored, not only apical 3 but apical 5 joints light which is whitish yellow, but these light antennal segments in. Tenthredo rubiobitava are reddish brown. Tenthredo rubiobitava Wei, 2002 is significaantly larger species, $13.0 \mathrm{~mm}$ (WEI 2002b), while the new 
species is only $9.4 \mathrm{~mm}$.

\section{List of other species}

Tenthredo subflava Malaise, 1945: 1 male, India, Chopta, 2680 m. 25. 06. 2015. leg. M. S. Saini.

Tenthredo shensiensis Malaise, 1945: 1 female, India, Chopta, 2680 m. 25. 06. 2015. leg. M. S. Saini. New record for India.

Tenthredo suta Konow, 1906: 1 female, India, Chopta, 2680 m. 23. 06. 2015. leg. M. S. Saini.

Tenthredo fredericki Taeger \& Blank, 1996: 1 female, India, Chopta, 2680 m. 14. 06. 2012. leg. M. S. Saini.

Tenthredo latifasciata Cameron 1877: 2 females, India, Chopta, 2680 m. 23. 06. 2015. leg. M. S. Saini. 
Authors express their grateful thanks to Dr. Hege Vardal.

\section{References}

EnsLin, E. 1920: Die Blattwespengattung Tenthredo L. (Tenthredella Rohwer). - Abhandlungen der Zoologisch-Botanischen Gesellschaft in Österreich, Wien 11(1): 1-96.

SAINI, M. S. 2007: Genus Tenthredo Linnaeus (Hymenoptera, Symphyta: Tenthredinidae). In: Indian Sawflies Biodiversity. Keys, Catalogue \& Illustrations. - Bishen Singh Mahendra Pal Singh, Dehra Dun 1: [1-7], 1-249.

WeI, M. \& NIE, H. 1998: Sixteen new species of the genus Tenthredo from Funiushan (Hymenoptera: Tenthredinidae). (In English, abstract in Chinese). - : pp. 188-200. In: SHEN, X. \& SHI, Z. (eds.): Insects of the Funiu Mountains Region (1). (The Fauna and Taxonomy of Insects in Henan Vol. 2). - China Agricultural Science and Technology Press, Beijing: 368 pp.

Wei, M., Wen, J. \& Deng, T. 1999: Nine new sawflies from Mt. Jigong (Hymenoptera: Tenthredinidae, Argidae). (In Chinese, abstract in English). - The Fauna and Taxonomy of Insects in Henan, China Agricultural Science and Technology Press 3: 21-32.

WeI, M., \& NIE, H. 2002a: Six new species of the genus Tenthredo L. (Hymenoptera: Tenthredinidae) from Henan province. (In Chinese, abstract in English). - pp. 154-162. In: SHEN, X. \& ZHAO, Y. (eds), Insects of the mountains Taihang and Tongbai regions. (The Fauna and Taxonomy of Insects in Henan, Vol. 5[2003]), China Agricultural Science and Technology Press.

Wei, M. \& Zhong, Y. 2002b: Nine new species of Tenthredo from Henan province (Hymenoptera: Tenthredinidae). (In Chinese, abstract in English). - : pp. 240-252. In: SHEN, X. \& ZhaO, Y. (eds), Insects of the mountains Taihang and Tongbai regions. (The Fauna and Taxonomy of Insects in Henan, Vol. 5[2003]), China Agricultural Science and Technology Press.

Zhelochovtsev, A. N. 1988: Otryad Hymenoptera - Pereponchatokrylye, Podotryad Symphyta Sidyachebryukhie, 7-234. In: Medvedev, K. H. (ed.) Opredelitel nasekomykh evropeiskoi chasti SSSR, Vol. 3 Hymenoptera, Part 6, Nauka, Leningrad.

ZomвoRi, L. 2016: Levéldarázs-alkaúak IV. Tenthredinoidea IV. In Fauna Hungariae 9. Hymenoptera I. Fauna Hungariae 174. 3/c booklet. Mondat Kft. and Hungarian Natural History Museum, Budapest. 160 pp. 